\title{
Perbandingan Motion Graphic dan Leaflet terhadap Peningkatan Pengetahuan Ibu Rumah Tangga dalam Menyimpan Obat
}

\section{Comparison of Motion Graphic and Leaflet to Increase the Knowledge of housewives in Medication Storage}

\author{
Nanda Puspita ${ }^{1}$, Fatiyah Syahida ${ }^{2}$ \\ Jurusan Farmasi, Politeknik Kesehatan Jakarta II, Indonesia
}

\begin{tabular}{l} 
ARTICLE INFO \\
\hline Article history: \\
Received date \\
10 Mar 2020 \\
Revised date \\
09 Apr 2020 \\
Accepted date \\
24 Apr 2020
\end{tabular}

Keywords:

Drug storage;

Health promotion;

Leaflet;

Motion graphic.

\section{Kata kunci:}

Penyimpanan obat; Promosi kesehatan; Leaflet;

Motion graphic.

\begin{abstract}
ABSTRAK
Inadequate storage of medicines at home is a common health problem in the community. Therefore, it is important to promote this issue through interesting media to increase knowledge related to medication storage. This study aims to compare conventional media (leaflet) with motion graphics in increasing knowledge of drug storage at home. Quasi-experimental research with a pretest-posttest design was applied to 45 housewives with similar education levels. In the initial stage, the leaflet group (23 people) and the motion graphic group ( 22 people) were given a pretest about medication storage, then were intervened with the media for 5 minutes, we're given a post-test afterward. The results showed there were significant differences in medication storage knowledge between groups that were exposed to motion graphics and leaflets (p-value $=0,029$ ). The median score of the knowledge in the motion graphic group was significantly higher $(85,71)$ than the leaflet group $(71,43)$. Motion graphics might be beneficial as an educational media to deliver message related to effective drug management for the community, especially housewives.
\end{abstract}

Penyimpanan obat yang tidak tepat di rumah merupakan masalah kesehatan yang umum terjadi di masyarakat. Oleh karena itu diperlukan edukasi melalui media promosi kesehatan yang menarik untuk meningkatkan pengetahuan terkait penyimpanan obat. Penelitian ini bertujuan untuk membandingkan media konvensional (leaflet) dengan motion graphic dalam meningkatkan pengetahuan penyimpanan obat di rumah. Penelitian eksperimental kuasi dengan desain pretest-posttest diterapkan terhadap 45 orang responden yang merupakan ibu rumah tangga dengan tingkat pendidikan yang homogen. Pada tahap awal, kelompok leaflet (23 orang) dan kelompok motion graphic (22 orang) diberi pretest tentang penyimpanan obat, kemudian diintervensi dengan media selama 5 menit, dan setelahnya diberi posttest. Hasil penelitian menunjukkan terdapat perbedaan signifikan pengetahuan penyimpanan obat antara kelompok yang diberi paparan motion graphic dengan media leaflet ( $p$-value $=0,029)$. Median skor pengetahuan kelompok motion graphic $(85,71)$ lebih tinggi dibanding kelompok leaflet $(71,43)$. Motion graphic dapat bermanfaat sebagai media edukasi terkait pengelolaan obat yang efektif bagi masyarakat, khususnya ibu rumah tangga.

Corresponding Author:

Nanda Puspita

Jurusan Farmasi, Politeknik Kesehatan Jakarta II

Email: nandapuspita28@gmail.com 


\section{PENDAHULUAN}

Upaya pengelolaan obat dalam masyarakat memerlukan pengetahuan yang cukup agar obat dapat digunakan secara tepat, aman, dan rasional. Salah satu aspek pengelolaan obat, yaitu penyimpanan yang benar, menjadi langkah penting agar obat tetap berkualitas sebelum digunakan. Studi tentang penyimpanan obat telah banyak dilakukan di berbagai negara, beberapa diantaranya menunjukkan bahwa mayoritas masyarakat masih memiliki pengetahuan yang kurang tentang penyimpanan obat yang benar (Gracia-Vásquez et al., 2015; Tsiligianni, Delgatty, Alegakis, \& Lionis, 2012). Obat yang tersimpan pada tempat yang bersuhu tidak sesuai anjuran kemasan (misal di dalam mobil atau dekat dapur) beresiko mengalami penurunan efikasi (Crichton, 2004). Di Indonesia, sebuah survei di wilayah Jakarta Timur menunjukkan 87 dari 295 kepala rumah tangga (29,5\%) menyimpan obat di tempat yang beresiko terkena panas dan tempat dengan kelembaban tinggi (Yunus, Puspita, \& Fajri, 2018). Oleh karena itu, diperlukan upaya edukasi kepada masyarakat terkait penyimpanan obat secara tepat.

Penyuluhan merupakan salah satu upaya promosi kesehatan yang dapat dilakukan untuk meningkatkan kesadaran masyarakat tentang pentingnya penyimpanan obat yang benar. Ikatan Apoteker Indonesia (IAI) menggalakkan program DAGUSIBU (dapatkan, gunakan, simpan, dan buang) agar masyarakat memperoleh informasi tentang pengelolaan obat yang baik di rumah. Berbagai media telah digunakan untuk promosi kesehatan ini, baik secara lisan (ceramah dan diskusi) maupun tertulis melalui media cetak (leaflet dan poster). Sejumlah studi promosi kesehatan menggunakan media cetak sudah banyakdilakukan (Agrimon \& Street, 2016; Jumilah, Jauhari, \& Ridha, 2013; Yustisa, Aryana, \& Suyana, 2014), tetapi studi yang khusus mengkaji tentang DAGUSIBU masih terbatas.

Saat ini, berkembang pula upaya promosi kesehatan melalui media sosial seperti Youtube, Instagram, dan Facebook. Lembaga kesehatan di beberapa negara telah memanfaatkan perkembangan media sosial sebagai langkah mengedukasi masyarakat terkait permasalahan kesehatan (Duke et al., 2019; Rahim, Ibrahim, A. Salim, \& Ariffin, 2019). Salah satu multimedia yang sedang berkembang di media sosial saat ini adalah video motion graphic. Media ini merupakan perpaduan teks, gambar animasi, dan suara yang umumnya digunakan sebagai 'explainer video' di dunia pemasaran. Namun penggunaannya kini meluas ke bidang lainnya, seperti hiburan, pendidikan, dan kesehatan. Motion graphic dinilai cukup mudah dibuat dengan menggunakan software desain yang tersedia seperti adobe illustrator dan adobe flash (Cone, 2013).

Indonesia merupakan negara berkembang dengan penetrasi internet yang cepat, termasuk dalam hal pencarian informasi kesehatan. Perilaku masyarakat mencari informasi kesehatan telah mencapai $51,06 \%$ dari seluruh penduduk (Infografis, 2017). Hal ini dapat menjadi peluang bagi penyebaran media informasi kesehatan khususnya edukasi pengelolaan obat melalui internet. Motion graphic adalah salah satu bentuk video animasi yang banyak tersebar di internet. Salah satu bentuk promosi kesehatan terkait obat yang menggunakan motion graphic adalah edukasi tanya 5-O yang diunggah secara resmi di akun Youtube Kementerian Kesehatan RI (Direktorat Jenderal Kefarmasian dan Alat Kesehatan, 2019). Pada studi sebelumnya, peneliti berupaya untuk mengembangkan media edukasi penyimpanan obat dengan desain motion graphic dan mengujinya pada responden ibu rumah tangga (Puspita \& Wardiyah, 2019). Penelitian ini merupakan kelanjutan dari penelitian sebelumnya yang bertujuan untuk membandingkan efektivitas media alternatif ini dengan media konvensional khususnya leaflet dalam meningkatkan salah satu aspek DAGUSIBU yaitu penyimpanan obat yang benar pada ibu rumah tangga.

\section{METODE}

Penelitian ini merupakan penelitian eksperimental kuasi dengan rancangan pretestposttest with comparison group. Penelitian dilakukan terhadap warga di wilayah kelurahan Jatimakmur, Pondok Gede, Bekasi pada minggu pertama bulan Oktober 2019. Responden dalam penelitian ini adalah ibu rumah tangga, berusia $\geq 18$ tahun, dapat membaca dengan baik, dan dapat mengakses media sosial. Dua kelompok dipilih dengan metode accidental sampling terdiri dari 23 responden yang mendapat perlakuan edukasi dengan leaflet dan 22 responden yang diberi tayangan video motion graphic. Materi teks tentang penyimpanan obat dibuat sama untuk kedua media, dengan memperhatikan tingkat keterbacaan (readability) menggunakan formula Gunning Fox index. Penilaian terhadap materi tertulis dilakukan dengan membagi jumlah kata dengan jumlah kalimat yang ada dalam satu 
paragraf. Rumus dari Gunning Fox index adalah sebagai berikut:

$0,4 \mathrm{x}\left[\left(\frac{\text { total kata }}{\text { total kalimat }}\right)+100\left(\frac{\text { kata kompleks }}{\text { total kata }}\right)\right]$

Dari materi yang disusun diketahui skor Gunning Fox test adalah 16,6 (di bawah 18) yang menunjukkan isi materi mengandung bahasa yang dapat dimengerti oleh orang dewasa umum. Sebelum diberi perlakuan, responden diberi pretest dengan kuesioner tentang pengetahuan penyimpanan obat untuk data baseline. Kuesioner terdiri dari 7 pernyataan tentang penyimpanan obat yang terkait langsung dengan isi media. Pernyataan dalam kuesioner diberikan dalam format benar-salah untuk menguji kepahaman responden terhadap informasi yang disajikan (tabel 1).

Tabel 1. Daftar Pernyataan Kuesioner terkait isi media leaflet \& motion graphic tentang penyimpanan obat di rumah

\begin{tabular}{|c|c|c|}
\hline No. & Pernyatan & B S \\
\hline 1. & $\begin{array}{l}\text { Obat sirup antibiotik sebaiknya } \\
\text { tidak disimpan lebih dari } 7 \text { hari di } \\
\text { dalam kulkas }\end{array}$ & \\
\hline 2. & $\begin{array}{l}\text { Sediaan salep atau krim racikan } \\
\text { sebaiknya tidak digunakan lagi } \\
\text { setelah } 6 \text { bulan }\end{array}$ & \\
\hline 3. & $\begin{array}{l}\text { Obat-obatan yang sering } \\
\text { diperlukan dalam perjalanan dapat } \\
\text { disimpan di dalam mobil agar } \\
\text { mudah dijangkau }\end{array}$ & \\
\hline 4. & $\begin{array}{l}\text { Obat luar dan obat dalam dapat } \\
\text { disimpan pada satu kompartemen }\end{array}$ & \\
\hline 5. & $\begin{array}{l}\text { Sediaan insulin untuk penderita } \\
\text { diabetes yang belum digunakan } \\
\text { sebaiknya disimpan di dalam } \\
\text { freezer }\end{array}$ & \\
\hline 6. & $\begin{array}{l}\text { Sediaan insulin yang sudah dibuka } \\
\text { baik digunakan atau tidak } \\
\text { sebaiknya dibuang setelah } 1 \text { bulan }\end{array}$ & \\
\hline 7. & $\begin{array}{l}\text { Sediaan tetep mata dapat disimpan } \\
\text { maksimal selama } 6 \text { bulan setelah } \\
\text { digunakan }\end{array}$ & \\
\hline
\end{tabular}

Selanjutnya, responden dari kelompok leaflet diberi waktu untuk membaca informasi penyimpanan obat yang tertera dalam media cetak tersebut. Sementara itu, responden dari kelompok motion graphic diminta untuk menonton tayangan edukasi penyimpanan obat yang telah diupload oleh peneliti melalui media sosial, Youtube. Durasi waktu yang diberikan untuk kedua perlakuan adalah sama, yaitu 5 menit. Pasca perlakuan, responden dari masingmasing kelompok menjawab posttest dengan pertanyaan yang sama dan dievaluasi skornya.
Untuk mengetahui ada tidaknya perbedaan rerata skor pengetahuan sebelum dan sesudah perlakuan masing-masing media, dilakukan uji $\mathrm{T}$ berpasangan (Paired T-test) apabila data terdistribusi normal atau Wilcoxon signed rank jika data tidak terdistribusi normal. Sedangkan untuk mengetahui perbedaan rerata skor antara edukasi dengan leaflet dan motion graphic, dilakukan uji $\mathrm{T}$ bebas (independent T-test) jika data terdistribusi normal atau Mann-Whitney jika data tidak terdistribusi normal. Perbedaan skor dinyatakan bermakna apabila $p$-value di bawah nilai signifikansi yang ditentukan $(0,05)$.

Penelitian ini dilakukan dengan menerapkan informed consent kepada responden sebagai tanda kesediaan terlibat dalam penelitian. Penelitian juga telah mendapat persetujuan etik dari komisi etik penelitian Politeknik Kesehatan Jakarta II (KEPK-PKJ II) dengan nomor ijin etik LB.02.01/1/KE/39/466/2019.

\section{HASIL}

Penelitian ini menguji efek intervensi edukasi melalui dua media yang berbeda, leaflet dan motion graphic. Responden merupakan ibu rumah tangga dengan rentang usia antara 16-68 tahun, dan berpendidikan SD sampai SMA. Sejumlah 45 responden terbagi menjadi dua kelompok dengan latar belakang usia dan pendidikan yang hampir sama baik dalam kelompok leaflet maupun motion graphic. Sebelum diberi intervensi, masing-masing kelompok responden diberi pretest untuk mengamati baseline knowledge tentang penyimpanan obat di rumah. Hasil penelitian menunjukkan tidak terdapat perbedaan bermakna pada rerata usia dan tingkat pendidikan responden. Demikian pula dengan nilai pretest sebagai baseline knowledge responden. Antara nilai pretest responden pada kelompok kontrol dan perlakuan tidak terdapat perbedaan bermakna ( $p$-value $=0,285)$ seperti tampak pada tabel 2 . Hal ini berarti kedua kelompok data berasal dari populasi dengan variasi yang sama dan memiliki kondisi yang homogen sehingga syarat penelitian terpenuhi. 
Tabel 2. Data Karakteristik Ibu Rumah Tangga selaku Responden pada Kelompok Media Leaflet dan Motion Graphic

\begin{tabular}{lrrr}
\hline \multirow{2}{*}{$\begin{array}{c}\text { Karakteristik } \\
\text { Responden }\end{array}$} & \multicolumn{2}{c}{ Kelompok } & Leaflet \\
\cline { 2 - 3 } & $\begin{array}{r}\text { Motion } \\
\text { Graphic }\end{array}$ & value \\
\hline Rata-rata usia & $\begin{array}{r}42,78 \\
( \pm 8,97)\end{array}$ & $\begin{array}{r}43,36 \\
( \pm 11,86)\end{array}$ & 0,853 \\
$(\mathrm{SD})$ & & & \\
\hline $\begin{array}{l}\text { Pendidikan } \\
\text { Tidak tamat }\end{array}$ & 9 & 3 & 0,053 \\
$\begin{array}{l}\text { SMA } \\
\text { Tamat SMA } \\
\text { sederajat }\end{array}$ & 14 & 19 & \\
\hline Skor pretest & 60,87 & 66,88 & 0,285 \\
\hline
\end{tabular}

Uji normalitas data terhadap selisih skor pengetahuan sebelum dan sesudah intervensi leaflet menunjukkan data terdistribusi normal sehingga selanjutnya dilakukan uji $\mathrm{T}$ berpasangan untuk kelompok leaflet. Berdasarkan tabel 3, hasil uji menunjukkan tidak terdapat perbedaan bermakna ( $p$-value $=0,076)$ skor pengetahuan penyimpanan obat sebelum dan sesudah diberi bacaan leaflet. Sedangkan kelompok motion graphic memiliki data tak terdistribusi normal sehingga dianalisis dengan uji non-parametrik. Hasil penelitian menunjukkan adanya perbedaan skor bermakna antara sebelum dan sesudah perlakuan. Data dianalisis dengan uji Wilcoxon signed rank dan menunjukkan adanya perbedaan bermakna pengetahuan responden sebelum dan sesudah diintervensi dengan motion graphic $(p$-value $=0,005)$.

Tabel 3. Hasil Perbandingan Pretest \& Posttest pada Kelompok Media Leaflet dan Motion Graphic

\begin{tabular}{llrl}
\hline Kelompok & $\begin{array}{c}\text { Penge- } \\
\text { tahuan }\end{array}$ & $\begin{array}{c}\text { Mean/Median } \\
\text { skor } \\
\text { (min-maks) }\end{array}$ & $\begin{array}{c}\boldsymbol{p} \text { - } \\
\text { value }\end{array}$ \\
\hline $\begin{array}{l}\text { Leaflet } \\
(\mathrm{n}=23)\end{array}$ & Pretest & 60,87 \\
& Posttest & $\begin{array}{r}(28,57-85,71) \\
70,81\end{array}$ & $0,076^{\mathrm{a}}$ \\
& & $(28,57-100)$ & \\
\hline $\begin{array}{l}\text { Motion } \\
\text { graphic } \\
(\mathrm{n}=22)\end{array}$ & Pretest & $\begin{array}{r}71,43 \\
(42,85-100)\end{array}$ & $0,005^{\mathrm{b}}$ \\
\hline
\end{tabular}

Analisis terhadap skor pengetahuan antara intervensi dengan leaflet dan motion graphic (tabel 3) menunjukkan adanya perbedaan signifikan $\quad(p$-value $=0,029)$. Median skor responden yang diberi tayangan video motion graphic lebih tinggi $(85,71)$ dibanding responden dalam kelompok leaflet $(71,43)$.
Tabel 3. Perbedaan Efek Penyuluhan melalui Media Leaflet dan Motion Graphic terhadap Pengetahuan Penyimpanan Obat di Rumah

\begin{tabular}{lcr}
\hline \multicolumn{1}{c}{ Kelompok } & $\begin{array}{c}\text { Median Skor } \\
(\text { min-maks })\end{array}$ & $\begin{array}{r}\boldsymbol{p} \text { - } \\
\text { value }\end{array}$ \\
\hline $\begin{array}{l}\text { Post test leaflet } \\
(\mathrm{n}=23)\end{array}$ & $71,43(28,57-100)$ & $0,029^{\mathrm{c}}$ \\
\cline { 1 - 2 } $\begin{array}{l}\text { Post test motion } \\
\text { graphic }(\mathrm{n}=22)\end{array}$ & $85,71(28,57-100)$ & \\
\hline
\end{tabular}

\section{PEMBAHASAN}

Penelitian ini merupakan salah satu dari sedikit penelitian yang menganalisis motion graphic sebagai media promosi kesehatan khususnya di bidang farmasi. Motion graphic merupakan media audio-visual yang saat ini berkembang penggunaannya untuk sarana komunikasi kesehatan. Media motion graphic dibuat dengan menggambar garis dan bidang dua dimensi melalui software desain seperti adobe illustrator atau adobe flash. Susunan gambar tersebut kemudian digerakkan dan diisi dengan suara maupun teks. Motion graphic lebih sederhana dari animasi pada umumnya. Fungsi motion graphic lebih pada penyampaian informasi berupa pesan teks kepada penonton. Dibanding video edukasi yang merekam orang di dalamnya, motion graphic memberi keluasan dalam menyunting konten/isi dan membutuhkan durasi yang lebih pendek untuk menyampaikan pesan yang sama. Motion graphic lebih memfokuskan penonton pada isi pesan teks dibanding gesture atau ekspresi orang di dalam video (Cone, 2013). Penelitian tentang motion graphic untuk media promosi kesehatan belum banyak dilakukan, tetapi terdapat beberapa penelitian tentang efektivitas media audio-visual lainnya yang memiliki karakteristik serupa motion graphic.

Penelitian dilakukan dengan teknik accidental sampling, salah satu teknik nonprobability sampling yang memudahkan peneliti dalam pencuplikan sampel. Responden yang berpartisipasi dalam penelitian adalah para ibu rumah tangga di kelurahan Jatimakmur, Kecamatan Pondok Gede, Bekasi. Penyuluhan tentang penyimpanan obat dengan media audiovisual merupakan metode pendidikan massa, dimana sasarannya bisa siapa saja. Namun penelitian ini berfokus mengambil responden ibu rumah tangga dengan hipotesis bahwa kelompok ibu memiliki peran penting dalam pengelolaan obat di rumah. 
Penelitian ini bermaksud membandingkan efektifitas media motion graphic dengan media konvensional yang telah banyak diteliti seperti booklet/leaflet. Dua kelompok responden yang masing-masing diberi leaflet (kontrol, $\mathrm{n}=23$ ) dan motion graphic (perlakuan, $\mathrm{n}=22$ ) diuji pengetahuannya tentang penyimpanan obat rumah tangga melalui kuesioner. Pada kelompok leaflet tidak terdapat perbedaan skor pengetahuan yang bermakna antara pretest dan posttest ( $p$ value $=0,076)$. Hasil penelitian ini berbeda dengan beberapa penelitian lain yang menggunakan leaflet sebagai media intervensi (Fatimah \& Musfiroh, 2014; Jumilah, et al., 2013). Penyuluhan dengan media cetak (leaflet dan poster) pada studi tersebut tetap menunjukkan perbedaan pengetahuan signifikan pada responden. Pada penelitian ini, terdapat beberapa kemungkinan, pertama pada saat penyuluhan dengan leaflet, responden mengalami kejenuhan membaca teks meskipun telah disusun dengan bahasa yang jelas dan awam. Hal ini terkait dengan sifat media cetak yang kurang menstimulus semua panca indera dalam proses pencapaian pengetahuan. Kedua, terdapat istilah bentuk sediaan obat yang kurang familiar bagi responden seperti penyimpanan supositoria dan injeksi insulin. Selain itu, penyajian informasi dalam leaflet hanya memudahkan penyaji tetapi kurang memperhatikan pemahaman pembaca. Kemampuan literasi yang rendah menurut sebuah studi juga menjadi hambatan bagi responden dalam menyerap informasi kesehatan (van Beusekom, Grootens-Wiegers, Bos, Guchelaar, \& van den Broek, 2016). Dalam penelitian menggunakan metode focus grup discussion (FGD) beberapa responden menuturkan bahwa mereka kurang percaya diri menginterpretasikan informasi yang mereka baca dari leaflet. Kekhawatiran dalam menterjemahkan informasi kesehatan ini adalah manivestasi dari rendahnya health literacy pada kelompok berpendidikan menengah ke bawah. Kelompok responden ini akan lebih memilih mendengarkan informasi (komunikasi verbal) dari tenaga kesehatan. Di negara berkembang seperti Indonesia, rendahnya budaya melek kesehatan (health literacy) pada masyarakat menjadi hambatan yang serupa (Notoatmodjo, 2003).

Penyampaian informasi kesehatan melalui media audio-visual memberi manfaat yang berbeda dari media cetak. Hasil analisis uji Mann whitney menunjukkan perbedaan skor pasca intervensi yang bermakna antara media leaflet dan video motion graphic ( $p$-value $=0,029)$. Median skor responden yang diberi tayangan video motion graphic lebih tinggi $(85,71)$ dibanding responden dalam kelompok leaflet $(71,43)$. Hasil penelitian ini sejalan dengan sejumlah penelitian tentang media audio-visual sebagai media promosi kesehatan. Menurut Suhertusi (2015)media film lebih efektif dalam meningkatkan pengetahuan ibu hamil tentang ASI eksklusif dibanding media leaflet ( $p$ value $=0,001$ ). Studi oleh Angelina dkk (2019) menunjukkan bahwa media animasi sebagai bentuk lain audio-visual juga mampu meningkatkan pengetahuan dan sikap ibu terkait gizi seimbang pada balita ( $p$-value $=0,000)$. Sama halnya dengan media audio-visual lainnya, motion graphic dalam penelitian ini melibatkan proses transfer informasi tak hanya melalui panca indera penglihatan tetapi juga indera pendengaran. Pada penelitian ini dalam waktu 5 menit masing-masing kelompok responden diamati kemampuannya menyerap infornasi. Seorang responden menuturkan bahwa mendengarkan informasi dalam motion graphic lebih mudah daripada membaca informasi tersebut di dalam leaflet. Peneliti menduga budaya masyarakat Indonesia yang lebih banyak terpapar informasi verbal serta budaya baca yang kurang ikut mempengaruhi proses penyerapan informasi tersebut.

Adanya proses belajar yang menstimulus lebih dari satu indera mampu meningkatkan penyerapan informasi dan mempertahankannya dalam jangka waktu lebih lama. Seperti ditunjukkan pada penelitian Schnellinger, et al., (2010) tentang edukasi penggunaan antibiotik yang tepat pada 246 orang tua di poliklinik anak. Studi tersebut menunjukkan bahwa selang 4 minggu dari intervensi pertama kali, responden yang diberi video animasi memiliki pengetahuan yang tidak berbeda bermakna dengan sesaat setelah intervensi. Sementara kelompok orang tua yang diberi pamflet memiliki penurunan pengetahuan. Dengan kata lain, dibanding pamflet, penggunaan video animasi menjaga pengetahuan tentang penggunaan antibiotik dalam jangka panjang.

Pada suatu proses pendidikan kesehatan menuju perubahan perilaku, terdapat beberapa faktor yang mempengaruhi antara lain metode, materi, pendidik, dan media yang digunakan (Notoatmodjo, 2010). Motion graphic merupakan media audio-visual yang tepat sasaran bagi masyarakat saat ini, khususnya ibu rumah tangga yang aktif mengakses internet. Media ini juga dapat dijadikan sebagai sarana edukasi penyimpanan obat di rumah dengan jangkauan luas karena dapat diakses siapapun dan dimanapun. Studi menunjukkan bahwa promosi kesehatan melalui media audiovisual dapat 
meningkatkan kemampuan melek kesehatan (health literacy) bagi masyarakat berpendidikan menengah ke bawah (Delp \& Jones, 1996; Latif, Ahmed, Amin, Syed, \& Ahmede, 2016; Yeung, et al., 2017)

Kelemahan dari penelitian ini adalah evaluasi pengetahuan dilakukan tepat setelah intervensi dan tidak dilakukan evaluasi jangka panjang terhadap pengetahuan responden. Selain itu penelitian ini juga belum mengukur sikap dan perilaku responden pasca intervensi dengan motion graphic.

\section{DAFTAR PUSTAKA}

Agrimon, O., \& Street, J. (2016). Developing Comprehensive Diabetes Education Materials for Structured Patient Education Programs in Primary Care Setting. International Journal of Public Health Science (IJPHS), $\quad 5, \quad 16$. https://doi.org/10.11591/.v5i1.4758

Angelina, C., Nuryani, D. D., \& Elviyanti, D. (2019). Efektifitas Pemanfaatan Media Gambar Bergerak dan Video Animasi terhadap Peningkatan Pengetahuan dan Sikap Ibu tentang Gizi Seimbang pada Balita. Jurnal Kesehatan, 10(2), 181-186.

Direktorat Jenderal Kefarmasian dan Alat Kesehatan. (2019). Cerdas Gunakan Obat dengan Tanya Lima $\mathrm{O}$. https://www.youtube.com/watch? $\mathrm{v}=\mathrm{aZmW}$ $\mathrm{xSYFk}-4 \& \mathrm{t}=30 \mathrm{~s}$

Cone, J. (2013). The language of Motion Design. Computer Arts.

Crichton, B. (2004). Keep in a cool place: exposure of medicines to high temperatures in general practice during a British heatwave. Journal of the Royal Society of Medicine, 97(7), 328-329. https://doi.org/10.1258/jrsm.97.7.328

Delp, C., \& Jones, J. (1996). Communicating Information to Patients: The Use of Cartoon Illustrations to Improve Comprehension of Instructions. Academic Emergency Medicine, 3(3), 264-270. https://doi.org/10.1111/j.1553-

2712.1996.tb03431.x

Duke, C. H., Yin, J., Zhang, X., Blankenship, E. B., Akuse, S. E., Shah, G. H., ... Fung, I. C. H. (2019). Adopting YouTube to Promote Health: Analysis of State Health Departments. The Permanente Journal, 23, 1-6. https://doi.org/10.7812/TPP/18-094

Fatimah, M., \& Musfiroh, M. (2014). Perbedaan

\section{SIMPULAN}

Promosi kesehatan terkait penyimpanan obat melalui media leaflet tidak signifikan dalam meningkatkan skor pengetahuan responden, sedangkan motion graphic dapat meningkatkan skor pengetahuan responden antara pretest dan posttest. Pengetahuan penyimpanan obat pada responden yang diintervensi dengan motion graphic berbeda signifikan dengan responden yang diintervensi dengan leaflet. Median skor pengetahuan kelompok motion graphic $(85,71)$ lebih tinggi dibanding kelompok leaflet $(71,43)$.

Media Promosi Kesehatan Booklet dan Video terhadap Keterampilan Deteksi Dini Kanker Payudara pada Wanita Usia Subur. Journal Universitas Sebelas Maret.

Gracia-Vásquez, S. L., Ramírez-Lara, E., Camacho-Mora, I. A., Cantú-Cárdenas, L. G., Gracia-Vásquez, Y. A., EsquivelFerriño, P. C., ... Gonzalez-Barranco, P. (2015). An analysis of unused and expired medications in Mexican households. International Journal of Clinical Pharmacy, 37(1), 121-126. https://doi.org/10.1007/s11096-014-0048-1 Infografis. (2017). Penetrasi dan Perilaku Pengguna Internet Indonesia tahun 2017. www.teknopreneur.com

Jumilah, J., Jauhari, A. H., \& Ridha, A. (2013). Efektifitas Media Poster terhadap Peningkatan Pengetahuan tentang Kesehatan Gigi. Jurnal Mahasiswa Dan Peneliti Kesehatan - JuMantik, 1-12.

Latif, S., Ahmed, I., Amin, M. S., Syed, I., \& Ahmede, N. (2016). Exploring the potential impact of health promotion videos as a low cost intervention to reduce health inequalities: A pilot before and after study on Bangladeshis in Inner-city London. London Journal of Primary Care, $8(4)$, 66-71. https://doi.org/10.1080/17571472.2016.12 08382

Notoatmodjo, S. (2003). Pendidikan dan Perilaku Kesehatan (1st ed.). Jakarta: PT.Rineka Cipta.

Notoatmodjo, S. (2010). Promosi Kesehatan: Teori \& Aplikasi. Jakarta: Rineka Cipta.

Puspita, N., \& Wardiyah. (2019). The Development of Motion Graphic as Education Material for Promoting Adequate Home Drug Storage. SANITAS, 
10(2),

92-101 https://doi.org/https://doi.org/10.36525/san itas.2019.10

Rahim, A., Ibrahim, M., A. Salim, F., \& Ariffin, M. (2019). Health Information Engagement Factors in Malaysia: A Content Analysis of Facebook Use by the Ministry of Health in 2016 and 2017. International Journal of Environmental Research and Public Health, 16(4), 591. https://doi.org/10.3390/ijerph16040591

Schnellinger, M., Finkelstein, M., Thygeson, M. V., Velden, H. Vander, Karpas, A., \& Madhok, M. (2010). Animated video vs pamphlet: Comparing the success of educating parents about proper antibiotic use. Pediatrics, 125(5), 990-996. https://doi.org/10.1542/peds.2009-2916

Suhertusi, B., \& Nurjasmi, E. (2015). Pengaruh Media Promosi Kesehatan tentang ASI Eksklusif terhadap Peningkatan Pengetahuan Ibu di Wilayah Kerja Puskesmas Lubuk Begalung Padang Tahun 2014. Jurnal Kesehatan Andalas, 4(1), 1722.

http://jurnal.fk.unand.ac.id/index.php/jka/a rticle/download/177/172

Tsiligianni, I. G., Delgatty, C., Alegakis, A., \& Lionis, C. (2012). A household survey on the extent of home medication storage. A cross-sectional study from rural Crete, Greece. The European Journal of General Practice, $\quad 18(1)$, 3-8. https://doi.org/10.3109/13814788.2011.60 4674 van Beusekom, M. M., Grootens-Wiegers, P., Bos, M. J. W., Guchelaar, H.-J., \& van den Broek, J. M. (2016). Low literacy and written drug information: informationseeking, leaflet evaluation and preferences, and roles for images. International Journal of Clinical Pharmacy, 38(6), 1372-1379. https://doi.org/10.1007/s11096-016-0376-4 Yeung, D. L., Alvarez, K. S., Quinones, M. E., Clark, C. A., Oliver, G. H., Alvarez, C. A., \& Jaiyeola, A. O. (2017). Low-health literacy flashcards \&amp; mobile video reinforcement to improve medication adherence in patients on oral diabetes, heart failure, and hypertension medications. Journal of the American Pharmacists Association, 57(1), 30-37. https://doi.org/10.1016/j.japh.2016.08.012

Yunus, Y., Puspita, N., \& Fajri, P. (2018). The Extent of Inadequate Drug Storage: A Household Survey in Jatinegara, East Jakarta. Asian Journal of Applied Sciences, 6(6). https://doi.org/10.24203/AJAS.V6I6.5556

Yustisa, P. F., Aryana, I. K., \& Suyana, I. N. G. (2014). Efektivitas Penggunaan Media Cetak Dan Media Elektronika dalam Promosi Kesehatan terhadap Peningkatan Pengetahuan dan Perubahan sikap Siswa SD. Jurnal Kesehatan Lingkungan, 4(1), 29-39. Retrieved from http://poltekkesdenpasar.ac.id/files/JURNAL

KESEHATAN LINGKUNGAN/Putu Fanny Yustisa1, I Ketut Aryana2, I Nyoman Gede Suyasa3.pdf 